\title{
INSTITUIÇÕES E COOPERAÇÃO SOCIAL EM DOUGLASS NORTH E NOS INTÉRPRETES WEBERIANOS DO ATRASO BRASILEIRO
}

\author{
Hélio Afonso de Aguilar Filho* \\ Universidade Federal do Rio Grande do Sul-UFRG \\ Pedro Cezar Dutra Fonseca** \\ Universidade Federal do Rio Grande do Sul-UFRG
}

Submetido em Janeiro 2010; aceito em Julho 2010

\begin{abstract}
Resumo
$\mathrm{O}$ artigo tem por objetivo resgatar a aproximação teórica entre o arcabouço institucionalista de Douglass North e os argumentos utilizados por intérpretes do Brasil de reconhecida orientação weberiana, como Sérgio Buarque de Holanda, Vianna Moog e Raymundo Faoro. Para tanto, privilegia o entendimento da relação entre instituições e cooperação social presentes na obra desses autores como variável relevante para explicar o desempenho de longo prazo da economia brasileira, bem como de seu relativo atraso.
\end{abstract}

\section{Palavras-Chave}

atraso econômico, Douglass North, Sérgio Buarque de Holanda, Vianna Moog, Raymundo Faoro

Classificação JEL

B31, B52, N16

\section{Abstract}

The paper aims to rescue the theoretical approach of the institutional framework of Douglass North and the arguments used by interpreters of Brazil recognized Weber's guidance, as Sérgio Buarque de Holanda, Vianna Moog and Raymundo Faoro. To this end, highlights the understanding of the relationship between institutions and social cooperation in the works of these authors as a relevant variable to explain the long-term performance of the Brazilian economy and its relative backwardness.

JEL classification codes: B31, B52, N16

Keywords: economic backwardness, Douglass North, Sérgio Buarque de Holanda, Vianna Moog, Raymundo Faoro

\footnotetext{
* Professor Adjunto do Departamento de Ciências Econômicas e Doutor em Economia da Universidade Federal do Rio Grande do Sul - Endereço para contato: Av. João Pessoa, 52 - Porto Alegre - Rio Grande do Sul CEP90.040-000 - Email: haaf73@yahoo.com.br

**Professor Titular do Departamento de Ciências Econômicas da Universidade Federal do RioGrande do Sul UFRGS, Doutor em Economia pela Universidade de São Paulo, Pesquisador do CNPq - Endereço para contato: Av. João Pessoa, 52 - Porto Alegre - Rio Grande do Sul - CEP 90.040-000 - Email: pedro.fonseca@ufrgs.br
} 


\section{Introdução}

A complexidade crescente resultante das novas formas de interação social fez da questão da cooperação humana um tema de significativa importância para as Ciências Sociais. No campo da economia, especificamente, o problema da organização social, seguindo longa tradição desde Adam Smith, é pensado do ponto de vista dos interesses e da tomada de decisão individual. Assim, dentro desta perspectiva, o egoísmo é o elemento central para compatibilizar interesses privados e interesses públicos, em que cada indivíduo, buscando seus próprios fins, contribui para a máxima realização coletiva.

Para se atingir a ordem social, preconizada pelos modelos econômicos, a única exigência é a aceitação, por parte dos envolvidos, das regras da propriedade dos bens negociados. Supõe-se, nesse caso, que os indivíduos já internalizaram o sistema de valores e os comportamentos apropriados para fazerem operar as regras fundamentais. Entende-se, também, que a aceitação e o cumprimento dessas regras não implicam custos. Essa concepção falha, no entanto, em negligenciar as instituições que asseguram os incentivos essenciais para a cooperação, garantindo a aceitação, por parte dos indivíduos, das decisões coletivas. Ademais, o reconhecimento de qualquer marco institucional, bem como sua manutenção, requer a incorporação à análise dos custos de transação negligenciados pelo tratamento da teoria econômica convencional.

Douglass North inicia sua análise econômica buscando entender os mecanismos que estruturam as relações sociais. O fundamental passa a ser a compreensão de que sem instituições não há intercâmbio político, social e econômico. As instituições reduzem as incertezas inerentes à interação humana fornecendo, por conseguinte, os incentivos para a cooperação. Dependendo do tipo de cooperação social que é estabelecido, pode-se ter incentivos maiores ao crescimento ou à estagnação econômica no longo prazo. Os tipos de cooperação existentes podem basear-se em mecanismos impessoais ou pessoais. Segue daí uma proposição importante da teoria de North: as instituições formam-se com diferentes graus de eficiência de sociedade para sociedade para promover a cooperação entre os agentes.

A questão da cooperação social é também tema presente na longa tradição ensaísta brasileira. Vários autores buscaram explicar as causas do descompasso social, econômico e político brasileiro, principalmente quando comparadas às do mundo ocidental de tradição inglesa. Este é o caso de autores de reconhecida inspiração weberiana, como Sérgio Buarque de Holanda, Vianna Moog e Raymundo Faoro, que entenderam as relações patriarcais e patrimoniais existentes ao longo da história do Brasil, como a fonte do seu personalismo, antítese da racionalidade econômica capitalista e do desenvolvimento econômico. 
O objetivo do presente trabalho é resgatar, a partir do arcabouço teórico institucionalista formulado por North, os tipos de cooperação social existentes no Brasil e sua relação com o "atraso" do país, tendo por base os autores antes mencionados. Nossa principal hipótese no campo da história das ideias chama atenção para a forte aproximação entre as principais teses de Douglass North sobre cooperação social e desempenho econômico de longo prazo das economias com as causas apontadas por esses autores brasileiros na busca da explicação para o referido descompasso. O termo "atraso" é utilizado como recurso retórico, implicando relatividade na análise comparativa, por necessitar de um padrão de referência, seja no tempo (uma linha evolutiva) seja no espaço (no caso, países que estariam mais "adiantados" ou "modernos"). Posto isto, entende-se que o elo entre a literatura voltada ao estudo do atraso do Brasil e North se torna possível porque, este último, mesmo partindo do arcabouço teórico neoclássico, amplia seu escopo com a introdução de noções como incerteza, custos de transação, altruísmo, path dependence. Ademais, North reconhece a existência de fricção nas trocas e, principalmente, de limitações cognitivas no comportamento humano, os quais são decisivos para explicar porque algumas economias conseguiram desenvolver-se e superar seus problemas estruturais (como a pobreza e as disparidades sociais) com mais rapidez e sucesso que outras. Quanto aos autores brasileiros, a primeira justificativa para sua escolha advém de possuírem um marco teórico comum, posto que todos eles procuraram entender as causas do descompasso histórico do Brasil à luz das ideias weberianas, o que pode ajudar também a ampliar a perspectiva institucional de North. Outra razão para a escolha desses autores é a disposição compartilhada por eles em fazer uma comparação explícita entre o Brasil com o caminho seguido pelos países anglo-saxões, a qual contribui para que suas teorias sejam mais facilmente sujeitas a comparações e ao estabelecimento de conexões com outras teorias de cunho mais geral. Entendemos que justamente este padrão presente em suas obras aparece explicitado em termos teóricos nos trabalhos de Douglass North.

O texto está estruturado da seguinte forma: depois desta introdução, a segunda seção apresenta o núcleo da argumentação novo-institucionalista de Douglass North; na terceira, apresentar-se-á a obra representativa típica de três interpretes weberianos do atraso brasileiro, a saber, Sérgio Buarque de Holanda (1999 [1947]), Vianna Moog (1973 [1954]) e Raymundo Faoro (1997 [1957]) e, junto com elas, a fundamentação institucionalista de North; na quarta seção são apresentadas as conclusões do trabalho. 


\section{Cooperação Social e Instituições em Douglass North}

O problema essencial tratado por North em Institutions, Institutional Change and Economic Performance ${ }^{1}$ foi formulado desde o surgimento da economia como disciplina autônoma. Esse consistia em saber como poderia ocorrer o intercâmbio econômico em uma sociedade onde existe uma multiplicidade de indivíduos com interesses diversos, cada qual produzindo de forma atomizada, sem referência a um planejamento pré-estabelecido. Pensar numa resposta ao problema é pensar, justamente, nos motivos indutores da cooperação social.

Em um mundo complexo, como o das sociedades atuais, em que há um número considerável de jogadores, em que o jogo não é repetido e a informação não é plenamente conhecida, fica difícil sustentar a solução competitiva dos modelos neoclássicos. Para realizar todo o potencial econômico de um ambiente de alta tecnologia, com uma divisão do trabalho bastante ampla e com interação impessoal, faz-se necessária outra solução. Por isto, North inicia seu tratamento do problema da cooperação tornando mais flexíveis alguns dos pressupostos comportamentais de análise da teoria neoclássica. $\mathrm{O}$ autor passa, então, a conceber um mundo em que os indivíduos operam com base em informações incompletas derivadas de modelos subjetivos que estão frequentemente errados. Concebe, também, um mundo em que a retro-alimentação de informações é igualmente insuficiente para corrigir o problema e em que as regras que regulam o comportamento humano não surgem espontaneamente ou, quando criadas, são por quem tem o poder de colocar em pauta os seus interesses.

Ao superar a simplicidade do mundo descrita pela teoria neoclássica, North firma o entendimento de que as instituições desempenham o papel de elo entre o individual e o coletivo, ou mais explicitamente como as regras do jogo, ao restringir e limitar o comportamento humano em uma sociedade, reduzindo as incertezas. Essas instituições, por sua vez, estão muito longe de promover o resultado ótimo descrito pela teoria neoclássica.

\section{A. Custos de Transação e Custos de Transformação}

Ao formular sua concepção institucionalista, North busca combinar uma teoria da conduta humana com uma teoria dos custos de negociação. Isto é, as limitações na racionalidade humana, refletidas numa baixa capacidade de processar, organizar e utilizar informações, consideradas junto às incertezas próprias do "deciframento" do meio,

\footnotetext{
${ }^{1}$ Para compreender as diferentes trajetórias econômicas ao longo do tempo, sua ênfase passa a recair, além dos fatores tecnológicos, em todos os fatores da conduta humana que constituem a civilização.
} 
implicam a existência de custos de transação positivos. Os custos de transação, por sua vez, requerem a existência de normas e procedimentos de simplificação do intercâmbio entre os indivíduos. Como os custos de transação fazem parte dos custos de produção, é necessário enunciar as seguintes relações: os custos totais de produção consistem em custos de transformação e custos de transação. Podem ser citadas como custos de transformação as entradas de recursos na forma de terra, trabalho e capital que participam na transformação dos atributos físicos de um bem (tamanho, peso, cor, composição química). Estes custos dependem da tecnologia empregada, e decorrem em grande parte dos valores e da cultura das sociedades, que estimulam ou brecam a utilização das técnicas mais produtivas assim como o desenvolvimento de novas.

Outra fonte de custos de transação ${ }^{2}$ positivos, além da racionalidade limitada dos seres humanos e das incertezas próprias do meio, é a possibilidade de que os agentes manifestem uma conduta oportunista, tentando fugir aos compromissos assumidos nos contratos. Os custos de transação podem ser divididos em dois tipos: os primeiros são os custos de mensuração (e outros surgidos antes que a transação seja concretizada), que se relacionam às dificuldades dos agentes em definir claramente o objeto da transação, ${ }^{3}$ os segundos são os custos de enforcement (ou seja, os vinculados com a efetivação daquilo que foi pactuado), que por sua vez vinculam-se, entre outras coisas, à incerteza que os agentes têm com relação à propriedade do bem a ser trocado e, portanto, relacionam-se com problemas de legitimidade da transação a ser efetuada (Gala, 2003).

De forma geral, em sociedades fundadas em densas redes de relações, por exemplo, os custos de transformação são altos e os custos de transação baixos. Isto porque os custos de verificação e de garantia dos direitos de propriedade são reduzidos em virtude dos vínculos entre os indivíduos possuírem natureza pessoal (Fiani, 2002). Em sociedades mais complexas, isto é, aquelas que contam com mercado de capitais desenvolvido e/ ou com empresas que empatam grande volume de capital fixo, nas quais as relações nos mercados são tipicamente impessoais, entretanto, os custos de transformação são baixos (o desenvolvimento do mercado permite a concorrência entre um maior número de agentes, promovendo a eficiência e a redução de custos), porém os custos de transação são altos. Para garantir o intercâmbio, é necessária uma maior intervenção deliberada na formulação de instituições, que a princípio são custosas. Na Figura 1, mostra-se o trade-off entre custos de transação e custos de transformação com que se defrontam as sociedades - os custos totais de produção são iguais aos custos de transação mais os custos de transformação.

\footnotetext{
${ }^{2} \mathrm{O}$ desenvolvimento da teoria dos custos de transação é a marca principal de Oliver Williamson e das pesquisas centradas nos aspectos microeconômicos da NEI. A análise canônica dos custos de transação encontra-se em sua obra As Instituições Econômicas do Capitalismo (Williamson, 1985).

${ }^{3}$ Incluíram-se nesta categoria os custos de obter a informação relevante para escolher fazer uma determinada transação e os custos de elaboração dos contratos.
} 
Figura 1 - Trade-off entre Custos de Transação e Transformação

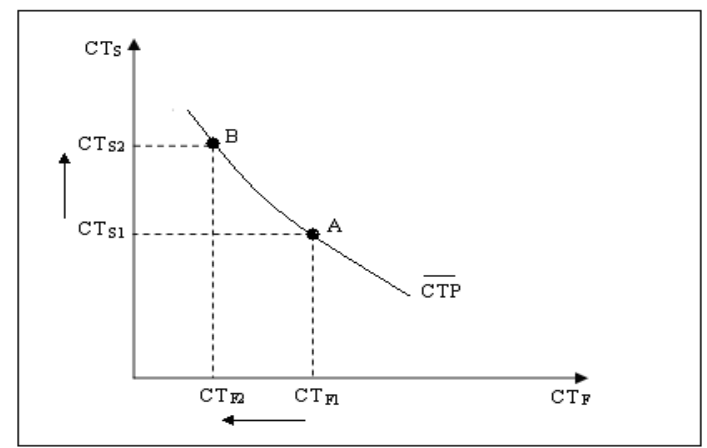

Nota: $\mathrm{CTP}($ Custos Totais de Produção $)=\mathrm{CT}_{\mathrm{F}}($ Custos de Transformação $)+\mathrm{CT}_{\mathrm{S}}($ Custos de Transação) Fonte: Elaborada pelos autores.

Na história, a passagem das formas mais elementares de intercâmbio para as mais complexas não é simples nem tampouco automática. A estrutura econômica das sociedades muda segundo uma enorme variedade de formas, que podem ser, não obstante, abordadas pela teoria dos custos de negociação apresentada nesta seção. ${ }^{4} \mathrm{O}$ mais importante é entender que o advento das sociedades modernas traz uma característica muito importante, ao mesmo tempo em que aumenta os custos de transação, reduz os custos de transformação.

\section{B. Instituições e Organizações}

As incertezas próprias do sistema econômico e os elevados custos de transação justificam a existência das instituições, que passam a coordenar, neste contexto, as ações coletivas, promovendo a estabilidade requerida para o intercâmbio humano. Na definição de North (1990, p. 03), as instituições são invenções humanas criadas para estruturar as interações politicas, econômicas e sociais ao longo do tempo. De forma geral, as instituições passam a consistir das limitações informais, regras formais e suas características de enforcement. As limitações informais incluem as convenções, as normas de comportamento e os códigos de condutas reconhecidos. As regras formais, em prin-

\footnotetext{
${ }^{4}$ Em seu esboço, North (1991) concebe um esquema em que a especialização do trabalho é analisada conjuntamente à evolução do comércio. As relações de troca ocorrem primeiramente de maneira local (restrita à vila), depois entre vilas e, por fim, atinge a longa distância. Esta evolução gera um maior nível de especialização e com ela surgem dois problemas: (i) o da agência; e (ii) o da garantia do enforcement. Para solucionar o primeiro, utilizam-se parentes para garantir a troca, tendo o negociante assegurado o retorno de sua carga através do resgate. Para o segundo, com o crescimento do tamanho e do volume do comércio, é necessário encontrar meios de forçar as partes envolvidas no intercâmbio exterior. A pirataria, as economias de escala, a urbanização e a distribuição ocupacional implicam contratos impessoais. Criam-se corpos voluntários e semicoercitivos para facilitar este tipo de comércio.
} 
cípio, diferem apenas em grau das regras informais; entretanto, sua criação ocorre por decisões de corpos políticos, jurídicos e econômicos, com base nos modelos subjetivos dos governantes e sujeitos principais e daqueles que têm o poder de colocar em pauta as regras voltadas a atender seus interesses. O enforcement refere-se às garantias de cumprimento obrigatório, ou seja, levanta-se a questão de quais são as possibilidades de as sanções previstas nas regras venham a ser efetivamente implementadas, caso seja necessário. Fazer cumprir contratos exige, portanto, uma terceira parte, geralmente uma organização com o monopólio do uso da força, o Estado.

Dentro do modelo estabelecido acima, se a informação e o cumprimento obrigatório não tivessem custo, não haveria função significativa para aquilo que propõem os jogadores ou organizações. As organizações podem ser vistas também como as entidades, idealizadas por seus criadores com o propósito de maximizar a riqueza, a entrada ou outros objetivos definidos pelas oportunidades que são oferecidas pela estrutura institucional da sociedade. As organizações incluem corpos políticos (partidos políticos, o senado, uma agência reguladora), corpos econômicos (empresas, sindicatos, cooperativas, casas familiares), corpos sociais (igrejas, clubes, associações desportivas) e órgãos educativos (escolas, universidades, centros vocacionais).

O pressuposto assumido pela NEI é que os contratos são inerentemente incompletos, formulados em um ambiente de incerteza, com os agentes mesclando altruísmo e, em algum grau, comportamento autointeressado e oportunista. Este último, quando muito, devido às poucas virtudes cívicas existentes na sociedade. Por isso, complementa-se a abordagem de North incluindo mais um elemento, um tipo de instituição informal: o capital social. Na definição de Putnam (1997, p. 177): O capital social diz respeito a características da organização social, como confiança, normas e sistemas, que contribuem para aumentar a eficiência da sociedade, facilitando as ações coordenadas. ${ }^{5}$

Quando North faz menção à necessidade de afastar as instituições que se baseiam em relações pessoais, está pensando no desenvolvimento de regras formais impessoais para regular os contratos e especificar os direitos de propriedade, mas Putnam (1997) mostrou posteriormente que sociedades operando estritamente com base nessas regras são marcadas por grandes desigualdades e pela vigência de princípios hierárquicos. Nesse tipo de sociedade, as regras são em geral verticalmente impostas e, para forçar o cumprimento dos contratos, há necessidade da existência de uma estrutura coercitiva demasiadamente onerosa. Existem limitações informais que diminuem enormemente os custos de transação, podendo, além disto, facilitar um grau maior de inovação tecnológica. Isto é, sociedades que dispõem de capital social amparado em valores que

\footnotetext{
${ }^{5}$ Também pode ser visto como um conjunto de valores ou normas informais partilhadas por membros de um grupo que lhes permite cooperar entre si.
} 
incentivam as associações impessoais e a cooperação complexa conseguem contornar o trade-off entre custos de transformação e transação, como especificado pela Figura 2. Por cooperação complexa entende-se aqueles tipos de cooperação que emanam dos sistemas de participação cívica e da reciprocidade generalizada, sem contrapartida no presente. Essas formas de interação social podem contribuir para aumentar o grau de confiança entre os membros de uma organização, justamente no ponto em que a cooperação é baixa e a coerção de um terceiro é demasiadamente onerosa.

\section{Figura 2 - Capital Social e Custos de Produção}

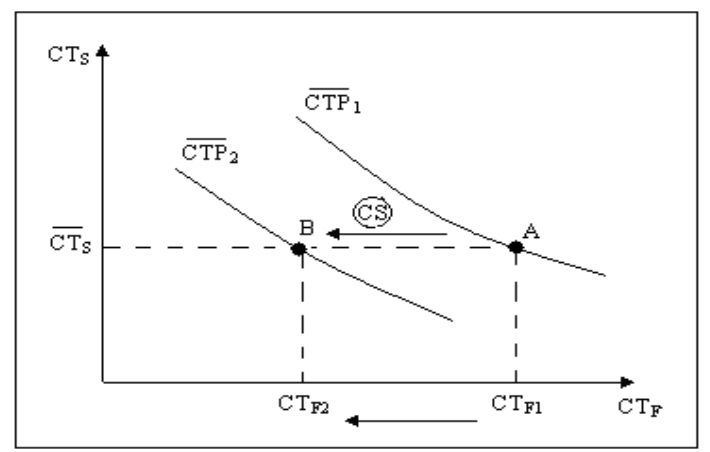

Nota: CTP $($ Custos Totais de Produção $)=\mathrm{CT}_{\mathrm{F}}($ Custos de Transformação $)+\mathrm{CT}_{\mathrm{S}}($ Custos de Transação $)$ $\mathrm{CS}=$ Capital Social

Fonte: Elaborada pelos autores.

Em geral, as regras formais e as limitações informais coincidem. Quando isso ocorre, pode-se dizer que as regras formais caminham no sentido de serem self-enforcing. Assim, tem-se como resultado que os custos de transação envolvidos na execução das normas sociais são reduzidos. São dois os motivos principais que levam à não coincidência entre esses mecanismos de coordenação. O primeiro é que, como salientado, as regras formais são formuladas no interesse daqueles que têm o poder de colocar em pauta as suas reivindicações; interesses esses muitas vezes contrários aos valores da maioria na sociedade. O segundo é que as limitações informais ganham certa estabilidade, e essa persistência no tempo leva ao conflito com as regras formais, causando importantes consequências na maneira em que mudam as economias. 


\section{Cooperação Social e Atraso Brasileiro na Perspectiva de Douglass North e dos Intérpretes do Brasil}

Apesar do aumento de complexidade e da diversidade de interesses que passam a coexistir nas sociedades com maior número de interações e atores sociais, existem nelas elementos que contribuem para manter a estabilidade e a ordem social. Nas ciências econômicas, tradicionalmente o egoísmo foi apresentado como o componente central para compatibilizar interesses privados e interesses públicos. Se todos agissem de forma autointeressada ao buscar o melhor para si, acabariam invariavelmente produzindo o melhor para todos. Essa solução permaneceu por muito tempo como um princípio da teoria econômica, até a teoria da escolha pública mostrar diversas situações ${ }^{6}$ em que o egoísmo autointeressado produz resultados contrários ao ótimo social preconizado por Smith.

Na análise de Douglass North, as instituições reduzem as incertezas próprias da interação humana fornecendo, por conseguinte, os incentivos para que haja cooperação e desenvolvimento econômico. No caso das sociedades complexas, o intercâmbio é garantido através de uma maior intervenção deliberada na formulação de instituições, necessárias até certo ponto, para o aprofundamento da divisão do trabalho e para aproveitamento das economias de escala. Nos "intérpretes" weberianos do Brasil, a impessoalidade é uma exigência do capitalismo racional, tanto na esfera do direito quanto na economia. Para estes, o personalismo português fez da colonização do Brasil um empreendimento bem sucedido, pelo menos até o surgimento do capitalismo industrial de cunho racional. A partir de então, esses autores entenderam essas mesmas instituições e o tipo de cooperação que elas fomentaram como as principais causas do "atraso" brasileiro. As próximas seções se ocupam justamente deste tema em cada um dos “intérpretes”. Enquanto Sérgio Buarque de Holanda (1999 [1947]) e Vianna Moog (1973 [1954]) têm um enfoque mais culturalista, Raymundo Faoro (1997 [1957]) preocupa-se mais com as configurações e a estrutura política da sociedade brasileira (Gertz, 2004). ${ }^{7}$

\footnotetext{
${ }^{6}$ Mesmo atribuindo-se aos agentes econômicos a racionalidade autointeressada pressuposta pela teoria econômica convencional, é possível conceber a existência de casos em que a interação entre estes agentes não produz o resultado ótimo preconizado na teoria econômica. Estes casos podem ser exemplificados a partir da existência de externalidades, geralmente envolvendo bens públicos e bens comuns. Para os bens públicos, há um incentivo para os agentes pegarem "carona" quando este bem é fornecido privadamente. No caso dos bens comuns, como as pessoas não pagam pelo uso que fazem dele, há incentivos para que ele seja usado excessivamente. A busca de eficiência por parte dos agentes pode gerar efeitos bastante indesejáveis sobre o bem-estar de toda a coletividade. Esse fato, associado ao fato de que nem todos os problemas possuem soluções de caráter técnico, levam à necessidade de se encontrar uma solução baseada em mudanças nas atitudes humanas, nas ideias, ou na moralidade.

${ }^{7}$ É vasta a literatura sobre as obras destes autores. Num esforço de síntese, arrolam-se: sobre Sérgio Buarque ver Cândido (1998), Vainfas (1998) e Veloso; Madeira (1999); sobre Vianna Moog conferir as obras de Leite (1969) e Souza (1999); sobre Raymundo Faoro verificar Barreto (1995); Galvan (2001) e Souza (2001).
} 


\section{A. Cooperação Social em Sérgio Buarque e Douglass North}

Nos capítulos iniciais de Raízes do Brasil, Sérgio Buarque ocupa-se em explicitar as causas do êxito português na colonização de uma região tão hostil ao colonizador branco europeu e, posteriormente, o malogro das instituições legadas por este em incorporar os avanços alcançados pela Europa Ocidental. Voltando à história da Península Ibérica, o autor destaca o tipo de cooperação social nela arraigado. Conclui que todas as formas de organização ou de associação implicando solidariedade e ordenação são contrárias à devoção dos ibéricos em relação à personalidade individual, ou mérito pessoal. $\mathrm{Na}$ descrição do autor, entre esses povos:

$O$ indice do valor de um homem infere-se, antes de tudo, da extensão em que não precise depender dos demais, em que não necessite de ninguém, em que se baste. Cada qual é filho de si mesmo, de seu esforço próprio, de suas virtudes... -e as virtudes soberanas para essa mentalidade são tão imperativas, que chegam por vezes a marcar o porte pessoal e até fisionomia dos homens. (Holanda, 1999, p. 32)

Uma condição fundamental destacada por North, ainda que não suficiente para promover o crescimento econômico, é a existência de ordem. Para que exista ordem é necessário que, em equilíbrio, todos os membros da sociedade tenham incentivos para obedecer e fazer valer as regras e que haja um número suficiente de pessoas motivadas para punir os eventuais desvios (North et alli, 2000). A carência de ordem e de coesão social para os ibéricos advém justamente da sua cultura da personalidade. A solidariedade entre eles existe apenas onde há vinculação de sentimento mais do que relações de interesses. Por outro lado, a concepção de vida desses povos, segundo Holanda (1999, p.32):

Espelha-se fielmente em uma palavra bem hispânica - "sobranceria"... É dela que resulta largamente a singular tibieza das formas de organização, de todas as associações que impliquem solidariedade e ordenação entre esses povos. E em terra onde todos são barões não é possivel acordo coletivo durável, a não ser por uma força exterior respeitável e temida aos homens.

Nas nações ibéricas, à falta da racionalidade da vida tão típica dos países protestantes, o princípio unificador teria sido representado pelo governo. As instituições existentes nelas são aquelas mantidas artificialmente por forças exógenas. Outra consequência da ausência de princípios de hierarquias e da exaltação do prestígio pessoal teria sido o 
favorecimento da prática de fidalguia. Advém daí então a repulsa ao trabalho regular e às atividades utilitárias, de onde decorre também a falta de organização dos portugueses e espanhóis. Assim:

Jamais se naturalizou entre a gente hispânica a moderna religião do trabalho e o apreço à atividade utilitária. Também se compreende que a carência dessa moral do trabalho se ajustasse bem a uma reduzida capacidade organização social. Efetivamente o esforço humilde, anônimo e desinteressado é agente poderoso da solidariedade dos interesses $e$, como tal, estimula a organização racional dos homens e sustenta a coesão entre eles homens. (Holanda, 1999, p. 38-39).

A própria burguesia lusitana, pelas facilidades de ascensão social, tomou como princípio de ação as aspirações e atividades da nobreza à qual desejava equiparar-se, desfazendo os ensejos de formar uma mentalidade específica, a exemplo de outros países. Esta repulsa é acentuada, na interpretação do autor, pela criação das tipologias do trabalhador e do aventureiro.

A descrição da eficiência do personalismo português em Raizes do Brasil está bem de acordo com o modelo teórico de North, para quem, em sociedades menos complexas, onde há um número reduzido de interações e de jogadores, o intercâmbio é personalizado e a ordem é mantida por meios de sanções pessoais, com reduzidos custos de transação. A cultura da personalidade do português, com sua plasticidade e pouca disposição para o trabalho, contrária ao ânimo que gera as empresas metodicamente racionais, teve, portanto, influência decisiva na formação e no sucesso da colonização do Brasil.

Assim como as sociedades mais simples, as sociedades complexas possuem regras, as quais, por meio da socialização e da sanção, atuam no sentido de fomentar a cooperação. Elas se baseiam, entretanto, numa forma de confiança mais impessoal ou indireta. Nesse tipo de sociedade, para que as organizações e os agentes possam apropriar-se das fontes lucrativas abertas pela tecnologia moderna, é necessário que o intercâmbio afaste as organizações sociais, políticas e econômicas centradas em laços familiares. Além disso, é necessário promover organizações e instituições voltadas a aparar as inseguranças associadas à extrema interdependência que caracteriza uma economia com alta especialização e mercados impessoais. 
As normas formais e informais reguladoras do intercâmbio em uma sociedade complexa representam apenas uma parte dos mecanismos que asseguram a estabilidade. A outra parte é representada pelas condições de enforcement, possibilitada pela ordem legal, na figura do Estado. O Estado é a organização-chave, tanto para tornar coercitivos os contratos e fazer valer a ordem quanto para fornecer os incentivos ao crescimento econômico. Esse segundo ponto diz respeito à forma como o Estado especifica os direitos de propriedade em troca de recursos fiscais. Com relação ao Brasil, com a predominância do modelo personalista e patriarcal, não era de se estranhar que houvesse ingerência da ordem familiar nos negócios públicos, com consequências sobre a distribuição de benefícios econômicos. Esse fato foi destacado pelo próprio Holanda (1999, p.146):

Não era fácil aos detentores das posições públicas de responsabilidade, formados por tal ambiente, compreenderem a distinção fundamental entre os domínios do privado e do público. Assim, eles se caracterizam justamente pelo que separa o funcionário "patrimonial" do puro burocrata conforme a definição de Max Weber. Para a gestão patrimonial a própria gestão política apresenta-se como assunto de seu interesse particular; as funções, os empregos e os beneficios que deles aufere relacionam-se a direitos pessoais do funcionário e não a interesses objetivos, como sucede no verdadeiro estado burocrático (...).

O que é descrito por North como um trade-off entre custos de transação e custos de transformação ganha, em Sérgio Buarque, como nos demais "intérpretes" weberianos do "atraso" brasileiro, uma explicação mais consistente. Esses autores sustentam também que o personalismo é a causa principal do atraso brasileiro, mas os motivos são outros. Isto é, a vantagem econômica do capitalismo com relação aos sistemas anteriores é que ele conseguiu desenvolver nos agentes uma atitude racional (submeter meios a fins previamente escolhidos) diante da atividade econômica. Essa atitude racional pode ser expressa tanto na quebra das relações tradicionais que condenavam a busca do lucro, como no rompimento das relações de hierarquia e dependência pessoal entre os agentes. Isto está de acordo com a interpretação que Dobb (1983) faz de Weber, para quem o capitalismo implica o desenvolvimento de uma racionalidade ou sistematicidade na busca do lucro, culminando num método de empresa. Em lugares onde não se desenvolveu este método, teriam persistido formas de intercâmbio entre os agentes marcados pelo tradicionalismo e pelo personalismo. Neste caso, o único tipo de capitalismo possível é aquele "politicamente orientado", no sentido de ser ele uma imposição de forças externas ao desenvolvimento da própria sociedade. Em muitos casos, acomodado segundo os interesses e necessidades de grupos locais ou externos. 
Nesta seção foi visto, tanto com base em North quanto em Sérgio Buarque, como os mecanismos que fomentam a cooperação e a ordem social trazem a estabilidade para a interação humana. Esses mecanismos dizem respeito à interação complexa entre as regras informais, as regras formais e as formas de execução. Na seção seguinte destacase semelhante aspecto nas obras de Vianna Moog e Douglass North.

\section{B. Cooperação Social em Vianna Moog e Douglass North}

No que se refere à interpretação de Sérgio Buarque, viu-se como a cultura da personalidade e o individualismo amoral, herdados de Portugal, condicionaram no Brasil a oposição entre despotismo e instituições democráticas. Isto é, a estabilidade requerida para refrear as paixões típicas do personalismo ibérico exigia sempre controles externos, vindos de cima para baixo. Vianna Moog também trabalha com os conceitos de Weber, com os quais busca alicerçar a correlação entre, em certo sentido, capitalismo e cooperação social na explicação do "atraso" brasileiro.

Para Moog, na explicação do desempenho econômico e social dos países no tempo, além dos fatores materiais, deveria contar também os fatores de ordem cultural. Desse modo, ganha importância o sentido inicial dado à descoberta do Brasil como um dos condicionantes do processo histórico. Esses motivos, segundo o autor, foram importantes porque eles conformaram o tipo de povoamento que se fixou no Brasil. Sua metodologia envolve a comparação entre as formações do Brasil e dos Estados Unidos, procurando desvendar suas diferentes trajetórias: enquanto para este último o sentido inicial foi orgânico e construtivo, para o primeiro foi predatório e extrativista. O interesse principal dos colonizadores brasileiros foi o de buscar riqueza fácil e rápida. Esse comportamento autointeressado estava em conformidade com o quadro de valores existentes em Portugal, que com suas conquistas na África e na Ásia adquiriu gosto pela aventura e pela desvalorização do trabalho. $\mathrm{O}$ incentivo à atividade predatória recebeu, inclusive, intenso apoio da Corte, que concebeu incentivos para se adentrar a terra em busca de metais preciosos, causando a dissolução das formas orgânicas de vida que se formavam no Brasil.

Quando não havia sinais de ouro grosso, era assim obstinado o bandeirismo, era inevitável que no século XVIII, quando o ouro, a prata, os diamantes foram de fato encontrados, o movimento bandeirante atingisse o climax e os ideais de conquista e de riqueza extrativa fácil fossem estimulados e prevalecessem sobre os ideais de riqueza orgânica, porventura encarnados do senhor de engenho ou no negociante do 
litoral. O simbolo do bandeirante teria de triunfar sobre os demais, ao contrário do que sucedeu nos Estados Unidos, onde a imagem idealizada do farmer como a do comerciante do século XVII, nunca se deixaram abalar ou vencer pela imagem idealizada do conquistador. (Moog, 1973, p.165)

É amplamente admitido por autores de diferentes paradigmas teóricos que nenhuma sociedade subsiste sem um conjunto de valores capazes de assegurar o mínimo de cooperação social. No caso do Brasil, com a predominância das bandeiras e de toda a sorte de atividade predatória, coube aos jesuítas, em primeiro lugar, a defesa da integridade nacional e sua estruturação moral e espiritual. Sem eles não teria sido possível a paz com o indígena e a defesa da costa do país. Outro elemento a contribuir para a estabilidade da sociedade brasileira foi a escravidão, a qual segundo Moog (1973, p. 179), fundou "a produção material dando certa medida de ordem, de educação, de sociabilidade, de polidez, de compostura, de higiene alimentar e de religiosidade". O triunfo final, entretanto, foi a idealização da ação do bandeirante como símbolo nacional.

A predominância do modelo mental bandeirante garantiu o sucesso inicial da colonização brasileira, alargando as fronteiras e permitindo a adaptação do colonizador europeu às condições inóspitas dos trópicos. Posteriormente, de fator impulsionador transformou-se em entrave ao desenvolvimento. Isto porque, segundo Magalhães (1974), a enorme dispersão na ocupação do território, fruto dessa mentalidade, teria impossibilitado o país de aproveitar de forma mais rotineira e racional as oportunidades abertas pela revolução industrial.

Do ponto de vista da teoria de Douglass North, a explicação provável para o descompasso brasileiro é que, nas condições de não cooperação e oportunismo que esse modelo mental incentivou, os agentes econômicos se empenharam cada vez mais em desenvolver conhecimento e aptidão para o ganho rápido e menos para a atividade econômica estável e ordinariamente lucrativa. Nesse caso, o problema ocorre porque na ausência de instituições que criem elos entre autointeresse e solidariedade de grupo, a transição para formas mais complexas de organização torna-se mais custosa, pois aumenta o prêmio para a deserção. Para Moog, assim como para Sérgio Buarque, o que predominou no Brasil foram valores bem particularistas, contrários àqueles que fomentam as relações cívicas. Para Sérgio Buarque esses valores tinham a sua predominância baseada no domínio do mundo rural sobre o restante da sociedade. No caso do autor de Bandeirantes e Pioneiros, o motivo principal, como visto, foi o predomínio do espírito predatório das bandeiras sobre as formas construtivas de trabalho orgânico. Em ambos os autores o ambiente criado não permitiu condições para o desenvolvimento dos atributos típicos de uma sociedade moderna. Um dos reflexos dessas condições é 
a não existência de uma esfera pública dissociada da ordem privada. Nas palavras do próprio Moog (1973, p.130):

Enquanto nós nos eximimos da responsabilidade e do dever de zelar a coisa pública, habituados que fomos a ver no governo o verdadeiro dono do País, o americano nunca deixa de considerar o país senão como um prolongamento de sua própria casa, estando sempre atento e vigilante e pedindo contas aos seus mandatários, ao presidente, aos deputados e senadores, pela administração e destino dos bens que lhes incumbe zelar. Enquanto nós, em matéria de sociabilidade e deveres sociais, a custo ultrapassamos o âmbito da família, o americano vive permanentemente em função da comunidade e, por vezes, exageradamente mais em função da comunidade que da família.

Um elemento que reforçou no Brasil o baixo estímulo à cooperação complexa foi a não existência de uma concepção de trabalho orgânico, agente poderoso em termos de estabilidade social. Isto é, na ausência dessa ética, o que se desenvolveu foram valores como as vaidades levadas a extremos doentios, o pedantismo, a suficiencia, o culto nacional de Malasarte, o herói que sem esforço e sem trabalho, somente pela habilidade, a intriga, o cálculo, a astúcia, resolve todas as situações (Moog, 1973, p. 215). Não é difícil entender que em um ambiente como esse os contratos serão formulados com custos elevados, tendo em vista a alta possibilidade de deserção.

Em síntese, da interpretação de Vianna Moog é possível depreender que o estímulo dado à atividade predatória foi um agente poderoso na consolidação das instituições e nos incentivos ao crescimento econômico brasileiro de longo prazo. A existência desse tipo de incentivo contrasta com aquilo que parte da teoria econômica recente considera como elementos fundamentais da estabilidade social e do crescimento econômico: o autossacrifício e o reconhecimento por parte dos agentes sociais das obrigações coletivas. A necessidade desses elementos cresceu, sobretudo, com o advento das sociedades modernas, onde é cada vez mais imperativa a presença de instituições voltadas a incentivar a cooperação social e baixar seu custo.

\section{Cooperação Social em Raymundo Faoro e Douglass North}

Para North, as instituições constituem-se na variável-chave para explicar a cooperação e os incentivos ao crescimento. As próprias organizações e jogadores têm sua razão de ser no conjunto de oportunidades estabelecidas pelo arcabouço institucional. O Estado é 
a fonte principal da estabilidade e da mudança institucional. Seus objetivos seriam dois: especificar as regras fundamentais da competição e cooperação e a criação de uma infraestrutura com o fito de garantir o respeito aos direitos de propriedade. Os requisitos estabelecidos para o estabelecimento da ordem e/ou da desordem, geralmente através do Estado, apresentam-se como os próprios fundamentos do crescimento econômico.

Em Faoro, a estabilidade, a organização jurídica e administrativa e, portanto, os direitos de propriedade no Brasil são heranças diretas da estrutura colonial imposta por Portugal. Com formação peculiar no contexto europeu, inclusive pela ausência de um feudalismo típico e de uma nobreza forte, as circunstâncias que moldaram o seu mundo possibilitaram que o Rei erigisse seu poder sobre uma estrutura de dominação patrimonialista, onde a Coroa, senhora de tudo, sustentava um séquito de guerreiros, delegados monárquicos e o incipiente quadro administrativo. Em consequência, a colonização e a conquista do território brasileiro tiveram sua fonte na vontade da burocracia, expressa na atividade "legalista" e regulamentar. Também com o recurso metodológico da análise comparativa, Faoro (1997, p. 122) firma o contraste: o inglês fundou na América uma pátria, o português fundou um prolongamento de Estado. A Inglaterra, após superar o feudalismo em sua transição ao capitalismo, teria sido hostil ao centralismo, com os colonos tendo chegado ao Novo Mundo já respirando o ar da liberdade, longe da tutela governamental.

No caso das colônias anglo-saxônicas, de acordo com North et alli (2000), a intervenção administrativa da Coroa, durante o período colonial, limitou-se apenas a prover bens públicos que incentivassem o comércio e a seguridade; as assembleias nacionais americanas trabalhavam juntas com o governo britânico. Assim, os EUA desfrutaram de uma ampla autoridade sobre os bens públicos locais, os direitos de propriedade, a liberdade religiosa e sobre o cumprimento dos contratos. As instituições do Império fixavam limites ao poder britânico em cada uma das colônias. Criou-se um amplo mercado integrado prevenindo as barreiras comerciais. Ademais, por causa da ameaça francesa, colonos e metrópole uniram-se em uma aliança comum, aderindo a um sistema de autonomia político-econômico semelhante à de um império federal. ${ }^{8}$ Nas colônias inglesas, ainda segundo North et alli (2000), a manutenção da ordem não dependia de um mecanismo centralizador que impunha sua vontade no interesse de fins estranhos

\footnotetext{
${ }^{8}$ Para North et alli (2000), a herança britânica teria elevado a importância dos direitos individuais políticos e econômicos, incluindo a representação política local. Mesmo quando colônia, os americanos experimentavam e acreditavam na liberdade individual, nos direitos privados de propriedade, bem como no limite ao poder do governo. Isto sustentado por um sistema de representação política local e as assembleias coloniais, bastiões principais da liberdade. Estes teriam sido plenamente compartilhados pelas colônias. A constituição americana teria permitido a vigência de um sistema federal que teria limitado firmemente os poderes do governo à provisão de bens públicos como: a seguridade nacional, a preservação do mercado conjuntamente com a estabilidade monetária. Em particular, a constituição reservou a maioria de seus poderes de regulação econômica e social aos estados, sujeitos a relações reforçadas pelo governo nacional ao levantamento de barreiras comerciais ao comércio interior.
} 
aos do colono. Isto porque a organização política e administrativa, bem como as demais instituições americanas, foram desde o princípio construídas com base nas tradições britânicas de self-government e de respeito às liberdades públicas. A estabilidade, portanto, baseava-se em um sistema de crenças compartilhadas que atuava como suporte do sistema federal.

O tipo de capitalismo que se desenvolveu no Brasil, fruto da dominação patrimonial, foi o capitalismo "politicamente orientado". Esta expressão, segundo Faoro, remete à comunidade política que comanda, conduz e supervisiona os negócios públicos. Esta camada é o estamento, marca dos indivíduos que aspiram aos privilégios concebidos pelo grupo, fundados no prestígio da camada e na honra social. Com o Estado usado em prol do estamento, as formas de intercâmbio e cooperação fomentadas no Brasil impediram o florescimento do cálculo econômico racional típico do capitalismo industrial e competitivo. De um lado, a realidade própria ao patrimonialismo, imbuída de uma racionalidade pré-capitalista, torna o particularismo e o favoritismo os principais critérios de ascensão social (Campante, 2003). De outro, ante uma realidade edificada de cima para baixo onde as leis, no geral, não refletem os costumes e tradições sociais tem-se a sociedade reagindo e criando seus próprios códigos de conduta. O efeito destes dois comportamentos é o de diminuir o grau de confiança nas instituições, com a consequente ampliação do espaço para comportamentos oportunistas (aumentando-se, assim, os custos de transação).

Vale ressaltar que a análise acima está de acordo com os argumentos de North (2003, p. 14), para quem: nos países da América Latina prevalece, desde os tempos coloniais, forte tendência à personalização das relações comerciais entre os indivíduos. Persiste a informalidade nos negócios, ao que ele acrescenta: Trata-se de uma questão cultural que dificulta até hoje a construção de um conjunto institucional baseado na objetividade capitalista. Assim, o modelo mental personalista vigente no Brasil adviria, dentro da lógica dos dois autores, da relação estabelecida entre Estado e sociedade. Em Faoro, este tipo de domínio impede o florescimento da calculabilidade e o pleno desenvolvimento das potencialidades dos agentes econômicos, porque o Estado não assume o papel de fiador de uma ordem jurídica impessoal e universal. Em North, este modelo personalizado de intercâmbio teria sido repassado às gerações posteriores, e legado como principal consequência a criação de um ambiente de baixa confiança e poucas oportunidades para investimentos de grande escala. Na linguagem weberiana, um empecilho à ordem racional e competitiva. Geralmente as firmas que atuam neste ambiente acabam incorrendo em custos políticos adicionais para não serem preteridas pelas concorrentes, aumentando os custos de transação e a ineficiência em termos globais deste tipo de sociedade. 
Em se tratando de sociedade brasileira é possível afirmar, com base no instrumental institucionalista, que tanto os custos de transformação quanto os custos de transação apresentam uma tendência a serem elevados, trazendo como consequência uma baixa eficiência produtiva da sociedade. Da leitura de Faoro, pode-se depreender que o Estado patrimonialista, ao exercer o seu domínio, incrementa a separação entre as decisões da esfera política e a sociedade, restringindo as liberdades e infringindo seus princípios:

Num regime onde não subsiste um grupo independentemente do poder do príncipe, onde a sociedade não está separada da organização de poder, as atividades econômicas, os interesses, os contratos não se reduzem, dentro deste contexto social, ao ganho, ao lucro e às vantagens materiais. Tudo se subordina à gloria, à honra, ao incremento dos valores do estamento. (Faoro, 1997, p. 67)

Em um ambiente como o descrito acima, o predomínio dos interesses estatais condiciona o alcance das regras constitucionais, e torna o ordenamento jurídico, de certa forma, expressão e veículo do poder particular e do privilégio, em detrimento da universalidade e da igualdade formal-legal (Campante, 2003). Não teria assim ocorrido nos Estados Unidos, onde a longa tradição de self-government herdada pelos colonos foi elemento importante na criação do sistema federativo. Este, além de ter garantido a ordem, criou um meio compatível com a autonomia política, a liberdade econômica e, consequentemente, propício ao crescimento econômico. Para Faoro, a centralização e o descolamento entre os interesses da camada dirigente e do povo sempre foram uma constante na história brasileira. Esta centralização, assim como para North, teria sido causa definidora tanto da estabilidade como do seu "atraso".

\section{Considerações Finais}

Para compreender as diferentes trajetórias econômicas ao longo do tempo, a ênfase de Douglass North recai, além dos fatores tecnológicos, nas variáveis da conduta humana que constituem a civilização. As instituições, nesta perspectiva, constituem-se no elemento que funde os interesses individuais e coletivos, permitindo o intercâmbio econômico, político e social e, desta forma, incidem sobre o maior ou menor crescimento econômico. Pela lógica dominante na teoria econômica, existem menos incentivos para a cooperação à medida que as sociedades se tornam mais complexas. Isto porque em grupos maiores é mais fácil disfarçar o comportamento oportunista e, além disso, os benefícios individuais da interação coletiva tornam-se menores. Por isto, para essas sociedades, em que existe um grande número de interações e jogadores, os custos de 
transação são elevados em decorrência da necessidade de se criar instituições que assegurem as transações impessoais e garantam o cumprimento dos contratos. Instituições baseadas em relações pessoais constituem-se, de outra forma, em empecilho para que essas sociedades reduzam seus custos de transformação, aproveitando as economias de escala e a maior divisão do trabalho.

Os "intérpretes weberianos" do Brasil também abordaram a questão do atraso focando nos incentivos institucionais existentes. O que é descrito por North como um trade-off entre custos de transação e custos de transformação ganha, nesses autores, outra ênfase. Esses sustentam também que o personalismo é a causa principal do atraso brasileiro, mas os motivos são outros. Isto é, a tipologia de capitalismo criado por Weber implica conceber esse sistema como dotado de uma racionalidade entre meios e fins que garantem sua eficiência comparativa. Essa atitude racional pode ser expressa tanto na quebra das relações tradicionais que condenavam a busca do lucro, como no rompimento das relações de hierarquia e dependência pessoal entre os agentes. Em lugares onde não se desenvolveu este método, teriam persistido formas de intercâmbio marcadas pelo tradicionalismo e pelo personalismo.

Para os autores brasileiros aqui analisados, o tipo de cooperação social fomentado no país ajudou na colonização de uma vasta região hostil ao europeu, mas impediu posteriormente o desenvolvimento da racionalidade capitalista. Para todos eles, a ausência desta racionalidade tem raízes históricas que remontam à colonização ibérica. Nela, o princípio unificador teria sido representado pelo governo. Assim, para a Holanda, as instituições existentes em Portugal e Espanha necessitaram artificialmente de forças externas para sua criação e permanência. A exaltação do prestígio pessoal teria favorecido a mania de fidalguia, fazendo nascer então a repulsa pelo trabalho regular e as atividades utilitárias, de onde decorre também a falta de organização destes povos. Para Moog, por sua vez, as relações capitalistas foram desvirtuadas pelo espírito predatório herdado das bandeiras. O mais significativo para esse autor é o sentido inicial atribuído à colonização brasileira: predatório, extrativista e quase só secundariamente religioso.

O ideal do conquistador acabou quase sempre triunfando sobre o orgânico e pioneiro (tomado no sentido de desbravador com ânimo de estabilidade). Para Faoro, finalmente, isto ocorre porque o Estado não assume o papel de fiador de uma ordem jurídica impessoal e universal; o domínio patrimonial exercido sobre a sociedade impede o florescimento da calculabilidade entre os agentes econômicos. A centralização e o descolamento entre os interesses da camada dirigente e do povo sempre foram uma constante na história brasileira. Mais uma vez o público confunde-se com o privado e o estamento burocrático adapta-se à ordem burguesa com a defesa do lucro, mas mantendo os valo- 
res avessos à ordem liberal e competitiva. Mesmo autores de formação mais próxima à tradição marxista do que propriamente weberiana, como Florestan Fernandes, assinalaram a dificuldade de constituição, em situação histórica como do Brasil, de móveis capitalistas do comportamento econômico (Fernandes, 1975, p.22).

Não constituiu nosso propósito avaliar a pertinência ou não das interpretações de Douglass North e dos autores brasileiros, mas resgatar a coincidência de argumentos entre eles. Embora o jogo retórico possa comportar diferentes argumentos de acordo com as diferentes audiências às quais se dirige (Bianchi, 2002), no caso vemos semelhanças na construção de ambos os grupos de autores, ainda que se possam supor diferentes públicos, uma vez que os autores brasileiros dirigiam-se primordialmente a leitores nacionais, ao contrário de North. Ademais, sabe-se que Douglass North esteve no Brasil em 1961, para conferência sobre história econômica e crescimento econômico regional (Boianovsky, 2009), todavia não se tem como afirmar ou rejeitar a hipótese que tivesse conhecimento das formulações de um ou de mais autores brasileiros aqui analisados. Pode-se admitir, no entanto, que todos eles, em menor ou maior grau, inspiraram-se nas ideias de Max Weber sobre o desafio da emergência da ordem racional e competitiva própria das sociedades capitalistas, com primazia do mercado e das relações impessoais.

Constatou-se em todos os autores que o tipo de cooperação social ensejado no Brasil foi baseado mais nas relações pessoais do que na impessoalidade propugnada pelo institucionalismo e por Weber. Em consequência, esse procedimento constituiu fator limitante para o aproveitamento e a difusão das potencialidades da tecnologia moderna, bem como empecilho ao desenvolvimento do cálculo econômico racional.

$\mathrm{O}$ expediente metodológico de todos estes autores foi o paradigma de desenvolvimento anglo-saxão. O recurso retórico da análise comparativa com outros países que servem de modelo ajuda a definir o seu entendimento de "atraso". Este é definido historicamente, com olhos no passado colonial, mas encontra no tempo presente destes autores a concreção ilustrativa do "modelo". Este olhar em duplo tempo (passado colonial/atualidade) e duplo espaço (Brasil/países anglo-saxões) revela uma forma bem peculiar de entender a formação econômica brasileira como "atraso" e traz embutida, ao explicitar as variáveis responsáveis por ele, o modelo a ser seguido.

\section{Referências}

Barreto, K. M. M. (1995), Um projeto civilizador: revisitando Faoro. Lua Nova, São Paulo, n. 36, p. 181-196.

Bianchi, Ana Maria (2002), For different audiences, different arguments: economic rhetoric at the beginning of the Latin American School. Journal of the History Economic Thought, vol. 24, n. 3, p.291-305. 
Boianovsky, Mauro (2009), Furtado, North and the New Economic History. Sessão Especial sobre "50 Anos da Formação Econômica do Brasil de Celso Furtado", XXXVII Encontro Nacional da ANPEC, Foz do Iguaçu, Dezembro 2009.

Cândido. A. (1998), A visão política de Sérgio Buarque de Holanda. In: Cândido, A. (Org.). Sérgio Buarque de Holanda e o Brasil. São Paulo: Fundação Perseu Abramo.

Dobb, M. H. (1983), A evolução do capitalismo. São Paulo: Abril Cultural.

Faoro, R. (1997), Os donos do poder: formação do patronato político brasileiro. São Paulo: Globo, 10a edição.

Fiani, R. (2002), Crescimento econômico e liberdade: a economia política de Douglass North. Economia \& Sociedade. Volume 11. No 1, Campinas.

Fernandes, Florestan (1975), A revolução burguesa no Brasil: ensaio de interpretação sociológica. Rio de Janeiro: Zahar Editores.

Gala, P. A (2003), Teoria Institucional de Douglass North. Revista de Economia Politica, volume 23, no (90), São Paulo, Abril-Junho.

Galvan, C. G. (2001), Colônia, estamento, capitalismo político: um enriquecimento de idéias na leitura livre de Faoro. In: Encontro Nacional de Economia Política, 6, São Paulo, 2001. Anais... São Paulo: FGV.

Gertz, René, Raymundo Faoro (2004), In: Axt, Gunter, Schuler, Fernando (eds.). Intérpretes do Brasil Cultura e Identidade. Porto Alegre: Editora Artes e Ofício.

Holanda, Sérgio Buarque de (1999), Raízes do Brasil. Companhia das Letras: São Paulo, 26a edição.

Leite, D. M. (1969), O caráter nacional brasileiro: história de uma ideologia. $2^{\mathrm{a}}$ ed. São Paulo: Pioneira.

Magalhães, João Paulo de Almeida (1974), EconomiA. Rio de Janeiro: Paz e Terra, V.1.

North, D. C. (1990), Institutions, Institutional Change and Economic Performance. Cambridge University Press, New York. . (1991), Institutions. Journal of Economic Perspectives. Volume 5, no 1 - Winter - p. 97-112. . (1994), Estructura y Cambio en la Historia Económica. Espanha: Alianza Universidad, 2a edição.

; Summerhill, William, Weingast, Barry R. (2000), Order, Disorder and Economic Change: Latin America versus North America. New Haven: Yale University Press.

North, D. C (2003), Para um país enriquecer. Veja, São Paulo, ano 36, n. 47, 26 nov.

Putnan, R. (1997), Comunidade e democracia: a experiência da Itália moderna. Rio de Janeiro: Fundação Getúlio Vargas.

Souza, J. (1999), A ética protestante e a ideologia do atraso brasileiro. In: Souza, J. (Org.). O malandro e o protestante. Brasília: UnB.

Souza, L. M. (2001), Raymundo Faoro: os donos do poder. In: Mota, L. D. Introdução ao Brasil: um banquete no trópico. 3. ed. São Paulo: Senac.

Vainfas, R. (1998), Historiador das representações mentais. In: Cândido, A. (Org.). Sérgio Buarque de Holanda e o Brasil. São Paulo: Fundação Perseu Abramo.

Veloso, M., Madeira, A. (1999), Sérgio Buarque de Holanda: raízes e rizomas do Brasil. In: Veloso, M., Madeira, A. (Org.). Leituras brasileiras: itinerários no pensamento social e na literatura. São Paulo: Paz e Terra.

Williamson, O. (1985), The Economics Institutions of Capitalism: firms, markets, relational contracting. New York: Free Press. 